\title{
Reply to Letter to the Editor, Reply to Yasri \& Wiwanitkit
}

We wish to thank Yasri et al. [1] for their interest and discussion regarding our recent publication '“Double-surgicalmask-with-slit” method: reducing exposure to aerosol generation at upper gastrointestinal endoscopy during the COVID-19 pandemic' [2]. As stated in that publication [2], our method adopts the same rationale that governs universal surgical mask use: to reduce airborne exposure to droplets and aerosols by introducing a physical barrier for truncation at source of the "shotgun effect" of aerosol spread [2,3]. Our method was never designed or claimed to replace other precautionary methods such as the use of any recommended personal protective equipment (PPE) or negative pressure rooms, but only to serve as an additional physical barrier, to potentially further reduce the risk of environmental contamination by fine droplets and aerosols. Through our routine practice, we also note that the "double-surgicalmask-with-slit," by its design, intrinsically leads to slight misalignment of the slits of the two masks, and this in turn enhances the curtain-like effect of the physical barrier around the scope, which further mitigates any potential "leakage" of droplets.

Although we are confident that with the adoption of increased preprocedural testing of patients for COVID-19, as recommended by more recent guidelines [4], the risk of potential environmental contamination and cross-infection would be reduced even further, it remains our opinion that the use of readily available, inexpensive, additional physical barriers; such as the one described by our group and by others [5], remains worthy of consideration for application in daily clinical practice.

\section{Competing interests}

\begin{abstract}
Alberto Murino has acted as a consultant for Boston Scientific and GI Supply. He has also received academic grants from Fujifilm, Aquilant Endoscopy, Norgine, and Olympus. Edward J. Despott has acted as a consultant for Boston Scientific and Ambu. He has also received academic grants and speaker honoraria from Fujifilm, Aquilant Endoscopy, Norgine, and Olympus. The other authors declare that they have no conflict of interest.
\end{abstract}

\section{The authors}

Nikolaos Lazaridis, Alexandros Skamnelos, Alberto Murino, Rocio Chacchi Cahuin, Nikolaos Koukias, Edward J. Despott

Royal Free Unit for Endoscopy, The Royal Free Hospital and University College London (UCL) Institute for Liver and Digestive Health, London, United Kingdom

\section{Corresponding author}

\section{Edward J. Despott, MD}

Royal Free Unit for Endoscopy, The Royal Free Hospital \& University College London (UCL) Institute for Liver and Digestive Health, Pond Street, London, NW3 2QG, United Kingdom edespott@doctors.org.uk Phone: +44-207-7940500

\section{References}

[1] Yasri S, Wiwanitkit V. Double-surgical-maskwith-slit and COVID-19 prevention. Endoscopy 2020: 96

[2] Lazaridis N, Skamnelos A, Murino A et al. "Double-surgical-mask-with-slit" method: reducing exposure to aerosol generation at upper gastrointestinal endoscopy during the COVID-19 pandemic. Endoscopy 2020; 52 : 928-929
[3] Maclntyre CR, Chughtai AA. A rapid systematic review of the efficacy of face masks and respirators against coronaviruses and other respiratory transmissible viruses for the community, healthcare workers and sick patients. Int J Nurs Stud 2020: doi:10.1016/ j.ijnurstu.2020.103629

[4] Gralnek IM, Hassan C, Beilenhoff $U$ et al. ESGE and ESGENA Position Statement on gastrointestinal endoscopy and COVID-19: An update on guidance during the postlockdown phase and selected results from a membership survey. Endoscopy 2020; 52 : 891-898

[5] Sagami R, Nishikiori H, Sato T et al. Endoscopic shield: barrier enclosure during the endoscopy to prevent aerosol droplets during the COVID-19 pandemic. VideoGIE 2020: 445-448

\section{Bibliography}

Endoscopy 2021; 53: 97

DOI $10.1055 / \mathrm{a}-1303-9528$

ISSN 0013-726X

published online 19.11 .2020

(c) 2020. Thieme. All rights reserved.

Georg Thieme Verlag KG Rüdigerstraße 14,

70469 Stuttgart, Germany 